\section{Opinion \\ Editing, Writing \& Publishing}

Check for updates

\title{
Independent, Publicly Funded Journals Adhering to Platinum Open Access Are the Future of Responsible Scholarly Publishing
}

\section{Srećko Gajović (1)}

OPEN ACCESS

Received: Oct 19, 2019

Accepted: Nov 11, 2019

Address for Correspondence:

Srećko Gajović

University of Zagreb School of Medicine,

Croatian Institute for Brain Research, Šalata 12 , HR-10000 Zagreb, Croatia.

E-mail: srecko.gajovic@hiim.hr

c) 2020 The Korean Academy of Medical

Sciences.

This is an Open Access article distributed under the terms of the Creative Commons Attribution Non-Commercial License (https:// creativecommons.org/licenses/by-nc/4.0/) which permits unrestricted non-commercial use, distribution, and reproduction in any medium, provided the original work is properly cited.

\section{ORCID iD}

Srećko Gajović (D)

https://orcid.org/0000-0001-8668-5239

\section{Disclosure}

The author has no potential conflicts of interest to disclose.
University of Zagreb School of Medicine, Croatian Institute for Brain Research, Zagreb, Croatia

Technical advances in digital publishing brought substantial changes to how we now deal with the essential element in producing new knowledge, namely, scholarly journals. Previously, paper-based journal issues were stored in libraries to be accessed by researchers. The printed issues could be borrowed, copies made, or reprints sent by colleagues. Every researcher used an impressive space for their own collection of selected publications to be on hand when needed, in particular during the process of new manuscript preparation.

All of these practices became obsolete as the off-line paper version was transformed into a virtual online-ready data file. This transformation also created the impression that having a non-touchable manuscript equivalent would incur no costs related to this type of publication. The dream that knowledge would now be available to all was conceptualized as open access and it was a logical consequence of free flow and replicability of digital files. The end of scholarly publishing as a sustainable business was predicted, which was far from the truth.1,2

The business model of scholarly publishing in the open access circumstance of digital publishing was established soon after, and it now represents a viable, profitable and rather lucrative way of economic activity. Digital publishing is indeed connected with the investment in proper presentation and handling of digital files. Moreover, scholarly publishing involves a substantial amount of highly valuable professional work to be provided by experts. All of this is to be translated to a realistic cost of scholarly publication. To sustain the notion of open access, where end users would access a digital publication for free, there is a clear need to find resources in order to cover incurrent costs, such as the so-called article processing costs (APCs). The covering of APCs is necessary for both the profit and non-profit model of open access, although only those for-profit would add a profit margin to the costs. For simplicity of billing procedures, the invoice for APCs would be issued to authors (referred as gold open access), or the total publishers' cost could be covered either by the scholarly association or by public funding (resulting in platinum open access without fees to be paid during the publication process).3,4

The above explanation is a well-known story repeated here with the purpose of showing that there was a logical sequence of events that has led us to the current situation in publishing. 
Open access is growing, both preserving the position of the publishing business, as well as providing the important added value of open access to all, which characterizes the current status of advanced scholarly digital publishing. However, the model described above relates to an advanced level of knowledge production typical for highly developed research communities. In contrast, the perspective of emerging research communities is rather different, which needs to be considered and addressed. The major fear, when open access is observed from the viewpoint of emerging research communities, is that open access could paradoxically add to the global inequalities in knowledge distribution rather than diminish it, which is quite opposite to what was intended by the notion of having knowledge accessible to all. ${ }^{5}$

Inequality in knowledge production is a rising global phenomenon. The number of high impact publications and in general, academic excellence, favors selected locations across the globe. ${ }^{6}$ The causes for this inequality are complex and circular. The standard of research publications is related to the number and level of grants attracted, selection of $\mathrm{PhD}$ students, technology transfer and innovativeness. The level of research excellence is further related to a country's economic status and outcomes, providing to the industry new knowledge to be translated to market products. Subsequently, although the inequality of knowledge production is evident by analysis of published papers, reflecting the ability of the community to produce knowledge, it can also be extended to the ability of the community to absorb knowledge to enhance own economy. Having no own knowledge to absorb, the community would have difficulty in absorbing and profiting from the global knowledge access provided by open access. The fact that open access provides knowledge to everybody, does not warrant that this knowledge would then contribute to the capacity of the community to absorb the knowledge.

To counteract knowledge inequalities and to diminish the gap between the best and the rest, APCs, which are to be charged to the authors as a part of the gold open access, represent a serious barrier. When we take Croatia as an example, Croatia is classified as a high-income economy by World Bank criteria, and subsequently has no reason to ask for any discount when invoiced for open access. ${ }^{7}$ However, Croatian researchers are not in an easy position. The APCs of open access are rarely eligible for funding or declared when requesting national financing. Due to the recent increase of APCs, publication costs in the total financing of a research group can be substantial. To give one example, our research group had the money to cover the APCs for a publication, however our collaborating group were rather upset about paying for open access, arguing that it would be wiser to invest in the consumables necessary to continue our research collaboration. In this situation, when it is unclear whether future experiments would be hampered by financial constraints, the argument for open access publishing is easily fading. In our research group, we have always given high priority to open access publications and have been successful in obtaining money for this purpose. However, we fully understand why our colleagues were not willing to jeopardize their experiments to support open access ideals.

In addition to this perspective, paying for APCs as a part of gold open access has elements of the "reverse Robin Hood" phenomenon. Robin Hood was famous for taking from the rich and giving to the poor, whilst the reverse Robin Hood takes from the poor and gives to the rich. The fact that major pro-profit publishers are registered in restricted locations of the developed world is just a part of the narrative that APCs are part of the "reverse Robin Hood" phenomenon. The perception of APCs as a fair compensation for the service provided by for-profit entities is difficult to argue in the context when it competes with the 
basic financial resources for experiments. Paying for APCs has an unintentional humiliating effect on researchers in academia, who are financed by public money, and after prolonged experiments, paper preparation, thorough review and paper acceptance, are not eligible for publishing without payment, which seems to be aimed at supporting the pro-profit industry.

Taking this perspective into account adds a surprising twist to predatory publishing being the unwanted distortion of gold open access. In predatory publishing, published papers are indeed open in the digital environment, however, they are not selected for publication in an ethical way. ${ }^{8}$ As the predatory publishers try to tap in to the profit source of established publishers, and are predominantly located in developing countries, one can assign the Robin Hood characteristics to them. This is even more exaggerated as some of the production centers of established publishers are indeed in the same countries hosting predatory publishers, making the difference in production quality negligible, and apparently, the analogous service provided in the same neighborhood in a predatory and non-predatory way. The barrier of an ethical approach of established publishers vs. a nonethical approach of predatory newcomers could be blurred by the clear pro-profit strategies of both sides providing quite a controversy between Robin Hood- and "reverse Robin Hood"-driven approaches. ${ }^{9}$

The fact that Croatia does not provide clear financial resources of public money to cover APCs to the publishers located outside of Croatia is counteracted by a rather positive notion, unrecognized even within Croatia's own confines. Namely, Croatia provides public money for the journals published in Croatia, almost all of them being published independently from the major publishers and being part of platinum open access, i.e., not asking any APCs from authors. The full text versions of published articles in all of these journals are available from a central Croatian repository Hrcak (https://hrcak.srce.hr/). Many of these journals are highly respected among research peers, including Biochemia Medica, Croatian Medical Journal and Food Technology and Biotechnology. The ethical and publishing standards are highly important for the functioning of these journals, and they are actively engaged in spill-over of these standards in the region. The important achievement of the Sarajevo Declaration endorsed by several journals from the region highlights the importance of integrity and visibility of independent journals. 10 The support provided by public financing originating from Croatian tax-payers is not exclusive to Croatian authors, as indeed the authors publishing in supported journals belong to countries from across the world. The journals' editorial boards understand the difficulties of authors coming from emerging research communities and in particular, the Croatian Medical Journal was the proponent of author-helpful policies, which provide a mentoring-like support for manuscripts having important results but lacking the corresponding features of style. 11 The major disadvantage of these journals is that they lack the level of marketing and community appeal that the major publishers have, and their impact factor cannot compete with the best (being 2.202; 1.624; and 1.517 respectively in 2018 for the 3 journals mentioned above). Nevertheless, these types of non-profit journals, financed by public money, governed independently and reflecting the needs of local and global communities, reveal the major characteristics of the openness connected to Responsible Research and Innovations. Similar to Responsible Research and Innovations, being connected to societal needs and offering free services to academic colleagues can be referred to as responsible scholarly publishing. The activities of the responsible journals accumulate publishing and ethical practice within the community and allow newly generated knowledge to be connected to the technology transfer necessary for the absorption of knowledge related to the economic and social progress of the community. 
Addressing the gap between advanced and emerging research communities cannot be achieved only by implementation in emerging communities of the practices generated in an advanced environment. Due to the time delay of acceptance and adaptation of these practices, even if they would be systematically applied, the gap would still grow. Subsequently, the only way to close the gap would be to apply a disruptive approach using advantages already present in emerging communities which would propel them by fast tracking even beyond the level of the current world leaders. These disruptive advantages grow in the cradle of emerging communities asking to be recognized and utilized. One of the advantages aimed at knowledge production is indeed the publishing model of independent journals supported by public money based on platinum open access. Being free of dependence on financial contribution from the authors, they can indeed concentrate on increasing ethical standards and scrutinizing submitted manuscripts at a higher standard. The latter would depend on the quality of reviewers. However seeing a higher purpose, reviewers would eventually move away from providing their free services to pro-profit businesses, and rather, move towards non-profit, community based, and ethically justified efforts, which we refer to here as responsible scholarly publishing. Without the intention to replace the current massive operations of major commercial publishers, the small, independent and publicly funded journals outside of mainstream business, could represent a "craft-beer revolution" in academic publishing, becoming carefully curated arts and crafts for presenting new knowledge. ${ }^{12}$

\section{ACKNOWLEDGMENTS}

The author thanks Dr. Jelena Marie Kežić, University of Zagreb School of Medicine, for her help in language editing of the manuscript.

\section{REFERENCES}

1. Barić H, Polšek D, Andrijašević L, Gajović S. Open access: is this the future of medical publishing? Croat Med J 2013;54(4):315-8. PUBMED | CROSSREF

2. Laakso M, Welling P, Bukvova H, Nyman L, Björk BC, Hedlund T. The development of open access journal publishing from 1993 to 2009. PLoS One 2011;6(6):e20961.

PUBMED | CROSSREF

3. Björk BC. Open access to scientific articles: a review of benefits and challenges. Intern Emerg Med 2017;12(2):247-53. PUBMED | CROSSREF

4. Gasparyan AY, Yessirkepov M, Voronov AA, Koroleva AM, Kitas GD. Comprehensive approach to open access publishing: platforms and tools. J Korean Med Sci 2019;34(27):e184. PUBMED | CROSSREF

5. Gajović S, Pochet R. The cost of scientific excellence: could it be expensive and out of reach? Croat MedJ 2016;57(5):413-4. PUBMED | CROSSREF

6. Posada A, Chen G. Inequality in Knowledge Production: The Integration of Academic Infrastructure by Big Publishers. Toronto: ELPUB; 2018.

7. World Bank Country and Lending Groups. https://datahelpdesk.worldbank.org/knowledgebase/ articles/906519-world-bank-country-and-lending-groups. Accessed October 15, 2019.

8. Memon AR. Revisiting the term predatory open access publishing. J Korean Med Sci 2019;34(13):e99. PUBMED | CROSSREF 
9. Amaral OB. All publishers are predatory: some are bigger than others. An Acad Bras Cienc 2018;90(2):1643-7. PUBMED | CROSSREF

10. Mašić I, Begić E, Donev DM, Gajović S, Gasparyan AY, Jakovljević M, et al. Sarajevo declaration on integrity and visibility of scholarly publications. Croat Med J 2016;57(6):527-9. PUBMED | CROSSREF

11. Gajović S. Resisting small cake phenomenon: sharing resources and knowledge makes you rich. Croat Med J2017;58(2):93-4. PUBMED | CROSSREF

12. Hindy S. The Craft Beer Revolution: How a Band of Microbrewers Is Transforming the World's Favorite Drink, reprint ed. New York, NY: St. Martin's Griffin; 2015. 